\title{
Choosing Local over Global during the Columbian Exchange
}

The diverse African societies and landscapes that existed before European contact were very different indeed than the ones we see today. Rich with natural resources that peppered ecological zones ranging from the wettest of forests to the driest of deserts, West Africa hummed with long-distance trade networks that brought all manner of goods to a wide array of village and urban consumers. Vibrant subregional trade propelled African goods to global marketplaces, supplying villagers with prestige goods from far afield and luring Europeans to its shores beginning in the fifteenth century (Green 2019; Mitchell 2005). Over the next few centuries, West Africa was to change dramatically, a story I continue in the following chapters. On the eve of these transformations, what was life like for villagers involved in long-distance trade? How did these experiences differ among villages and social groups? Was their everyday experience one of scarcity, plenty, or something in between? How did this change as Europeans landed on the coast, ushering in one of the largest-scale global exchanges in history?

Foodways of the early Atlantic period (c. 1400-1650) have mostly been considered under the rubric of the Columbian Exchange, and are illustrative of the ways in which scarcities of the present are assumed to have also characterized the past. American crops like maize and cassava are staple foods across sub-Saharan Africa today, and their presence alleviates food security concerns for many. Because of the important role of these crops in food security today, many scholars have surmised that they were adopted to meet such needs in the past. The context into which these new foods were adopted is rarely considered. As we know from materiality studies (Ogundiran 2002; Stahl 2002; Thomas 1991), understanding context is central to accessing how new goods were received. More than that, bringing local contexts to the forefront provincializes Eurocentric perspectives that would otherwise privilege the role of European explorers in spreading these new crops (Carney and Rosomoff 2009; 
La Fleur 2012). Considering local tastes and contexts helps us understand the choices that people made, and helps us evaluate whether scarcity defined peoples' experiences of food. To these ends, in this chapter I consider three interrelated questions: Were people desperate for the higher yields of maize or the dependable harvests of cassava? What were the environmental conditions at the time of the adoption of these crops? And how did preexisting food preferences shape peoples' responses to their arrival?

The arrival of Europeans also marks the beginning of our written archives for regions in the savanna and southwards to the coast (Arab records from the interior begin much earlier, starting in the ninth century $\mathrm{AD}$ ), and most considerations of the adoption of American foods have relied heavily on these sources (e.g., Alpern 1992, 2008; La Fleur 2012; McCann 2005). Most historical sources have focused on the coastal entrepôts where European and African traders lived in close proximity rather than on the vast majority of territory outside of these zones of direct interaction. Because these sources were penned by European men, they provide only a partial view of how these new foods were adopted by the local cooks and farmers. In this chapter, I offer a different view of the Columbian Exchange, one that focuses on countering certain stereotypes of Africa as a scarce place. Through the archaeological and food remains at two villages, I reveal how Banda weathered a severe drought through a strong economy that afforded people access to the local foods they preferred.

\section{BEYOND CROSBY: THE COLUMBIAN EXCHANGE}

The importance of American foods in Africa is more obvious than in any other continent of the Old World, for in no other continent, except the Americas themselves, is so great a proportion of the population dependent on American foods. Very few of man's cultivated plants originated in Africa ... and so Africa has had to import its chief food plants from Asia and America.

-ALFRED CROSBY, THE COLUMBIAN EXCHANGE, 2003

The potential genetic resources for agriculture in Africa were also unbalanced. Of large-seeded grass species ... that were potentially domesticatable cereal crops ... Africa had only four, none of which would be one of the world's primary grains in the 20th century ... therefore, Africa had to overcome an early liability, which, of course it eventually did by adopting exotic crops...

-JAMES MCCANN, MAIZE AND GRACE, 2005

The Columbian Exchange refers to the biological and cultural exchanges that occurred in the centuries after Columbus mistakenly landed on the shores of the Americas. Popularized by Alfred Crosby's 1972 book, which was revised in 2003, the exchange is understood to have operated on a scale and with consequences that make previous world systems seem minor by comparison. Animals, plants, 
people, diseases, commodities, and knowledge passed between the previously isolated Western and Eastern hemispheres. Illustrative of the impact on present foodways are the facts that before the Columbian Exchange there were no tomatoes in Italy or potatoes in Ireland; both crops were domesticated in the Americas and found new audiences and new cultural significance once they were adopted in Europe.

Africa's contributions to and benefits from the Columbian Exchange are less well known. Though Crosby devotes only three speculative pages to the African continent, his interpretation has proved remarkably tenacious, as seen in the juxtaposition of quotes above. McCann (2005) also draws on Jared Diamond's (1999) environmental determinist argument, which like many explanations of crop adoption in Africa accord environments more agency than the humans who fashioned them (La Fleur 2012). This is in part simply a limitation of archive: we know much more about the properties of different crops and environments than we do about the people who decided to adopt and modify them centuries ago. Unfortunately, when information is especially limited, reasoning based on the scarcity slot tends to fill in the gaps. Both quotes referenced above imply that Africans were incapable of developing their own crops (scarcity slot tenet 2), and consequently, lacked sufficient calories to feed their populations (scarcity slot tenet 1).

Yet, even by the time of Crosby's first writing, archaeologists had shown that Africans had indeed developed quite an impressive array of domesticated plants and animals thousands of years prior to the Columbian Exchange, including pearl millet and sorghum (deWet and Harlan 1971); we now know the range of adaptations were even more impressive (Marshall and Hildebrand 2002; Neumann 2005). McCann $(2005,40)$ underplays indigenous crops by noting they are not of significance to global markets, but this is more of a statement of their political value than of their capabilities. ${ }^{1}$ The most valued foods, on a global scale, tend to originate from regions of power, therefore the marginal role of African crops is not surprising given the uneven geopolitical landscape of the twenty-first century. In this chapter, I illustrate that the African domesticates pearl millet and sorghum were essential in the great civilizations that preceded European interventions on the continent and remained so until very recently. Understanding the role of African crops prior to these interventions is critical in situating their potential contributions in the future (chapter 6).

Crosby's reasoning betrays a second generalization: that African crops were not capable of meeting food security needs, or at very minimum, did not produce a meaningful surplus (see also Goody 1977; Goody 1982, 58-60). Echoes of this kind of reasoning can be found in McCann (2005) and Wilks (2004), who credit the rise of the Asante state to the introduction of maize and its ability to produce a large surplus (chapter 3). As de Luna details $(2016,8)$, this obsession with surplus comes from a worldview that celebrates capitalism and mercantilism, and, in a classic Othering move, equates lack of surplus with savagery and, I would argue, scarcity. Yet surplus is also the product of a certain kind of agriculture (monocropping) 
to fulfill a certain economic goal (export). Other kinds of agriculture may well be better suited to different economic goals (e.g., risk reduction) that do not rely on agricultural products as major exports (see the introduction, chapter 5). In this chapter, I evaluate the economic and environmental contexts of crop adoption during the Columbian Exchange to determine food security levels and thus evaluate the need for surplus.

If Crosby's portrayals of African crop adoption are inaccurate at best, what alternate models are available? While heavily influenced by Crosby, McCann's (2005) Maize and Grace provides an ambitious, continent-wide view of how people in diverse situations across the continent adopted maize. Three important volumes push back at Crosby's main arguments: Judith Carney's (2002) Black Rice: The African Origins of Rice Cultivation in the Americas, Carney and Nicholas Rosomoff's (2009) In the Shadow of Slavery: Africa's Botanical Legacy in the Atlantic World, and James La Fleur's (2012) Fusion Foodways of Africa's Gold Coast in the Atlantic Era. These authors emphasize the role of African agency in deciding whether or not to adopt new crops. This is an elegantly simple but important point, one which had long been made in the case of European adoptions of American crops: in all but the most desperate of circumstances, people have some decision-making power over what they eat (de Waal 1989). As my starting point for this chapter, I assume that the vast majority of people maintain some degree of choice over what they ingest. In the next section, I begin by highlighting the pros and cons of new and local grains that would have informed peoples' decisions. I review historical evidence of the use of existing foods and adoption of new ones on the Ghanaian coast. I then move to Banda to understand the role of local versus global crops during the mid-second millennium AD.

\section{LOCAL VERSUS GLOBAL GRAINS}

Worldwide, more maize is grown today than any other crop, and its popularity extends to the African continent. Originally domesticated in the American tropics, maize has tropical adaptations that make it ideal for tropical parts of West Africa and southern Africa (La Fleur 2012, 4; McCann 2005; Miracle 1966). Given the global importance of maize, it is not surprising that it has also received the most scholarly attention in Africa, as evidenced by McCann's (2005) recent book. If we were to rely on maize's botanical qualities alone, we might agree that it is, as McCann's title, Maize and Grace, suggests, the "grace" of Africa, enabling the continent to persist despite the hardships of the last several centuries. To McCann and Crosby, maize's success is due to its potential to produce high yields, and the short time required for the plant to reach maturity. But we must be mindful of the currency used to assess maize's agronomic value. Although two crops of maize can be produced per year, this double production schedule means that labor costs are also doubled, and labor has often been the limiting factor in African 
agricultural production (Hopkins 1973). While maize is capable of producing more calories per hectare than many other grain crops, people do not always choose the most economical choice. Instead, local taste preferences and food security play major roles in whether or not people adopt new crops. In emphasizing maize and other foreign crops, many researchers have underappreciated the rich capabilities of African grains and their potential to support large populations. In this section, I review the costs and benefits of maize alongside those of pearl millet and sorghum, two African crops that were cultivated for millennia prior to maize's introduction. This kind of comparison allows us to understand the tradeoffs that informed farmers' and cooks' decisions whether or not to adopt maize. This discussion will, in turn, be used to help understand why people in Banda adopted maize at the rate and to the extent that they did.

Pearl millet (Pennisetum glaucum) was the first domesticated plant in the continent, and has been cultivated in Ghana for over three thousand years (D'Andrea, Klee, and Casey 2001). It remains an important staple in the northern half of the country. Pearl millet is the sixth-most important crop on a worldwide scale, and the third most important in the African continent (National Research Council $1996,77,80)$. The grain is extremely drought tolerant and enables agriculture in even the most depauperate conditions across Africa and India, though it is less cultivated than maize because it is comparatively low-yielding and has not received nearly as much research support despite being a risk-averse choice for farmers (National Research Council 1996, 79, 97). It is nutritious, containing both a fair amount of protein for a grain crop (9-21\%) and more oil than maize. Pearl millet is also versatile: it can be steamed and eaten, used to make porridges and beer (National Research Council 1996, 81), and even consumed as uncooked flour (chapter 5). The late-maturing (140-90 day) variety is widely grown throughout the interior savanna; early maturing (80-9o day) millet is found in the far northern reaches of the country, where it is the first crop of the season (rather than maize as in the south). Pearl millet generally grows in areas with 250-800 millimeters of yearly rainfall (Brunken, de Wet, and Harlan 1977, 163), but in Ghana tends to be cultivated in moister locales with an average rainfall per year of 1,00o millimeters.

Sorghum or guinea corn (Sorghum bicolor) is an African domesticate that is a principal cereal in the interior savanna where, like pearl millet, it is produced primarily for domestic use and local sale. Sorghum is usually planted on more fertile land, being interplanted as a late crop with maize (or, in the north, with early millet); its yields on poor land are moderate. There are a few quick-maturing varieties (110 days), but most are longer-maturing, requiring 140-90 days. Compared to pearl millet and maize, sorghum is much more tolerant of wet conditions (Staff Division of Agriculture 1962, 370) and even of waterlogging (House 1995). It is not surprising that in Banda in recent years, as rainfall has been unpredictable and thus damaging to both maize and pearl millet, sorghum has emerged as the most dependable yielder (chapter 5). Sorghum is widely grown in areas that receive 
1,000 millimeters or more of annual rain, and is best suited to areas reaching 80-1,400 millimeters of rain a year, but can grow with as little as 254 millimeters or as much as 3,050 millimeters (De Wet and Harlan 1971, 130-31). If grown together, pearl millet and sorghum complement one another nicely, as millet does well even in the driest of conditions, and sorghum in situations that are too wet for millet.

How do the costs and benefits of sorghum and pearl millet compare to those of maize? Pearl millet and sorghum are overall more nutritious than maize. They also fare better in storage, since maize's high moisture content increases storage loss. Maize is also prone to insect and pest damage (Forsyth 1962, 394-96). Because pearl millet and sorghum have long coevolved with local pests, these crops may be better suited to pest management (although improved maize varieties may have some of the same qualities). Maize is highly demanding of soil fertility; over the longterm, significant investment in maize production could have negative consequences for land fertility. Finally, one of the more concerning long-term tradeoffs of maize adoption is its susceptibility to drought at key points in its life cycle, particularly during tasseling. Indigenous crops like pearl millet and sorghum, on the other hand, are well known for their drought resilience, meaning that these crops tend to produce higher yields in savanna environments (Miracle 1966, 208). In terms of labor, estimates vary significantly based on environmental factors, with Miracle's (1966, 207-13) comparisons generally seeing maize and sorghum as similar in terms of labor requirements and pearl millet as more costly. The initial processing of maize, which involves removal of the kernels from the cob, is easier than the same stage for pearl millet or sorghum, decreasing requisite time and labor costs. These savings may be lost in later stages of processing, particularly grinding or pounding into flour, which Banda women told me is more laborious for maize than for pearl millet.

Comparing yields of maize to sorghum and pearl millet is complicated by environmental factors as well as labor availability. In Ghana in recent decades, maize is a high-yielding crop par excellence, particularly with the application of fertilizers, yielding 350-800 pounds per acre. Native pearl millet (200-600 lb./acre) and sorghum (300-70o lb./acre) yield consistently less, and respond less well to fertilizer (Staff Division of Agriculture 1962, 369-72). However, synthetic fertilizers would not have been available at the time of maize's introduction several centuries ago. Miracle $(1966,207-8)$ suggests that maize is actually a comparatively low yielder in savanna and forest margin environments because of its proneness to drought. And while maize lends itself more readily to intensification, labor costs may have been a limiting factor in many African situations (Hopkins 1973). Sorghum and pearl millet make much more sense when people choose extensification strategies.

Maize's most significant advantage is its ability to produce a crop more quickly (three to four months) relative to pearl millet and sorghum (five to six months; but see below regarding early-maturing millet). In tropical West Africa, this short maturity time lines up perfectly with the two-peak rainfall pattern of equatorial regions, so that two harvests can be grown per year rather than just one, potentially doubling yields. In terms of food security, the timing of maize's maturity is critical: 
it is ready to harvest as early as July or August, which falls during a period of food shortage known as the hungry season gap (McCann 2005; Miracle 1966). The hungry season gap is created in part by the maturity schedule of indigenous cultigens like yams, which in wooded savanna regions like Banda are not ready until August or September, while sorghum and millet are usually harvested in November and December (chapter 5 ). The first crop of maize is ready precisely when people need it most, in July, when previous grain stores are running low prior to the maturity of other indigenous staples. Considering all of these factors, it seems likely that maize may have been adopted as a stopgap crop to prevent seasonal food insecurity or as a way to intensify agriculture in situations where labor was available.

While it is tempting to rely on the botanical qualities of maize as compared to those of local grains to explain maize's adoption, agriculture is a social and environmental technology that is intricately related to the political and economic contexts in which it operates (Guyer 1984, 1988). While several excellent reviews chronicle the existing data on American crop adoption in West Africa (Alpern 1992, 2008; Gallagher 2016), few works take full stock of the political, economic, and environmental contexts into which these crops were introduced. This is in part the shortcoming of the review article genre, but it also expresses a limitation of archival sources. An unintended consequence of this limited archive is that such adoptions appear to have taken place within a blank cultural canvas. The few archaeological studies that do exist mostly date to periods that were centuries after maize's initial introduction (Gijanto and Walshaw 2014; Kelly 1995; Maggs 1982; Norman 2009).

\section{FOODWAYS IN COASTAL GHANA IN \\ THE EARLY ATLANTIC ERA}

Coastal Ghana in the late sixteenth and early seventeenth centuries is one of the few places in Africa where written historical sources allow the reconstruction of foodscapes in the decades immediately after the introduction of some Atlantic crops, particularly maize. One excellent primary source (de Marees 1602 [1987]) and La Fleur's (2012) recent book on fusion foodways together provide a relatively high-resolution picture of foodways based on historical and linguistic data. These sources help re-create a partial image of coastal foodscapes that provides a broader regional foodscape for Banda, and they demonstrate how new crops played variegated roles across time and segments of society. While many new crops were introduced during the first century or two of European encounters (e.g., plantain, sweet potato, etc.; Alpern 1992; 2008; Gallagher 2016; La Fleur 2012), I focus on maize, since this crop sheds unique light on food security and food choice in the early Atlantic period.

Dutchmen Pieter de Marees visited coastal Ghana in 1601, and his relatively detailed description of foodways and agriculture provides one of the best primary sources for this period. In multiple places, he mentions that people along the coast had a sufficient food supply (de Marees 1987, 41), a point omitted by the 
historians who rely on this source. Yet he also details that not everyone enjoyed the same access to preferred foods. The elites seem to have had primary access to particular kinds of meat (chicken, goat, ox, and venison) (42). Yams are mentioned as the most common food of Africans (164). This starch-rich tuber would have provided more than ample carbohydrates (contra McCann's [1999, 119] suggestion that the forest was lacking in this regard; see chapter 3 ). Other plant foods noted by de Marees included millie (likely pearl millet), rice (probably African Oryza glaberrima), bananas, beans, palm oil, and possibly sweet potatoes $(40,159)$. Spices included ginger and grain of paradise (Aframomum melegueta), a spice grown only along the coast and highly sought after in medieval Europe (160).

In terms of daily foodscapes, women were apparently responsible for both procuring and making food. Each day they threshed and ground only enough millet for the day's meals (40). Men grew the crops, working first on the headman's fields before their own, for which they were repaid in food, drink, and merriment (111). De Marees (110) describes their agricultural cycle: planting millie and maize after a period of storms followed by heat, most likely at the onset of the rainy season (the translators note that this is after the transitional period between dry and wet seasons). The millet, he reports, "grows and flowers within three months, after which it is cut and left on the field for another month in order to dry" (112), which seems to indicate early-maturing millet. This is important, for it suggests early-maturing varieties were on the coast, and would have effectively prevented a hungry season gap from an agronomic perspective. If so, there was likely no gap that maize needed to fill, and here it is notable that indeed de Marees mentions no such shortage. Lacking a hungry season, maize is a solution in need of a problem. What seems probable is that maize was cultivated in the same schedule as early maturing millet, which it may have eventually come to displace.

De Marees devotes a chapter to the introduction and adoption of maize, which would have been a novel crop to both Europeans and Africans at the turn of the seventeenth century. He mentions that pearl millet was the grain Africans always had grown, and that they made do with it prior to the Portuguese arrival, when maize was introduced. By the time of his arrival, maize grew in abundance, and some Africans ground it with pearl millet, sometimes eating a half-and-half mixture, which was apparently prepared into a bread (113). ${ }^{2}$ Maize produced two crops per year. He mentions both small and large maize growing, of colors including white, black, yellow, purple, and more. It is unclear what he meant by large and small maize; La Fleur $(2012,93)$ interprets this as representative of multiple maize varieties, but it seems likely to the translators (114n5) and to me that at least one referred to sorghum, which is otherwise conspicuously absent from his account. Sorghum comes in a range of colors, including the hues described by de Marees. This diversity is more likely for sorghum, which had long been cultivated in West Africa, than for maize, which due to its recent and limited introduction was probably subject to a severe genetic bottleneck. Maize and sorghum plants 
look practically identical until flowering, so it is highly likely that these two were confused by de Marees, who was not a botanist (the same oversight may well plague other chroniclers like Bowdich [(1819) 1873]; see chapter 3).

La Fleur (2012, 55-61) suggests that it was the Portuguese, not local Africans, who were plagued by food scarcity, particularly in the early days of their settlement in the mid- to late fifteenth century. Supplies of familiar foods-wheat, wine, and olive oil-from Europe were not dependable, making the fledging coastal fort of Elmina completely dependent on African farmers. The Portuguese were, however, highly suspicious of unfamiliar foods, and avoided them when possible. Imported, familiar foods were likely claimed by the fort's elite leadership, while the Portuguese of low rank as well as the Africans they had enslaved most likely relied on local produce. That preferred foods were often unavailable meets two of the three criteria for at least periodic food insecurity, and may have been perceived as quite the hardship despite the ready availability of African foods. In contrast, local African elites were fascinated by new foods, often trading items of high value to gain access to culinary novelties (La Fleur 2012, 63). This contradicts modern understandings of African tastes as tied to quantity rather than novelty (de Garine 1997), suggesting a very different socioeconomic setting. While the details of these encounters and adoptions remains shrouded in mystery due to the limited nature of historical archives for this early period, what we do know suggests a significant inversion from traditional historiography of Africa during the Columbian Exchange. In this instance, it was Europeans rather than local Africans who experienced food scarcity and were in need of carbohydrates.

The written record helps us understand some of the brushstrokes on the cultural canvas into which maize arrived. The adoption of new crops was clearly structured by existing and emergent socioeconomic inequalities, as well as existing food preferences, culinary practices, and agricultural techniques (La Fleur 2012). The canvas can be brought to life by investigating what people did in the villages and households into which new crops, particularly maize, were introduced. Examination of plant remains from archaeological sites provides one of the few ways to understand how maize was adopted at a household level. Only recently have archaeologists began to address this issue directly through examining the crops remains themselves as well as their economic, social, and environmental contexts.

\section{FOODWAYS AND POLITICAL ECONOMY \\ IN BANDA, AD 1400-1650}

In Banda, much of our data on daily life before and during the Columbian Exchange comes from two towns we know by their archaeological site names, Ngre Kataa and Kuulo Kataa, named after their proximity to modern-day villages. ${ }^{3}$ These are among the largest villages occupied during the early Atlantic era in the Banda area, which we know archaeologically as the mid- to late Kuulo phase (AD 


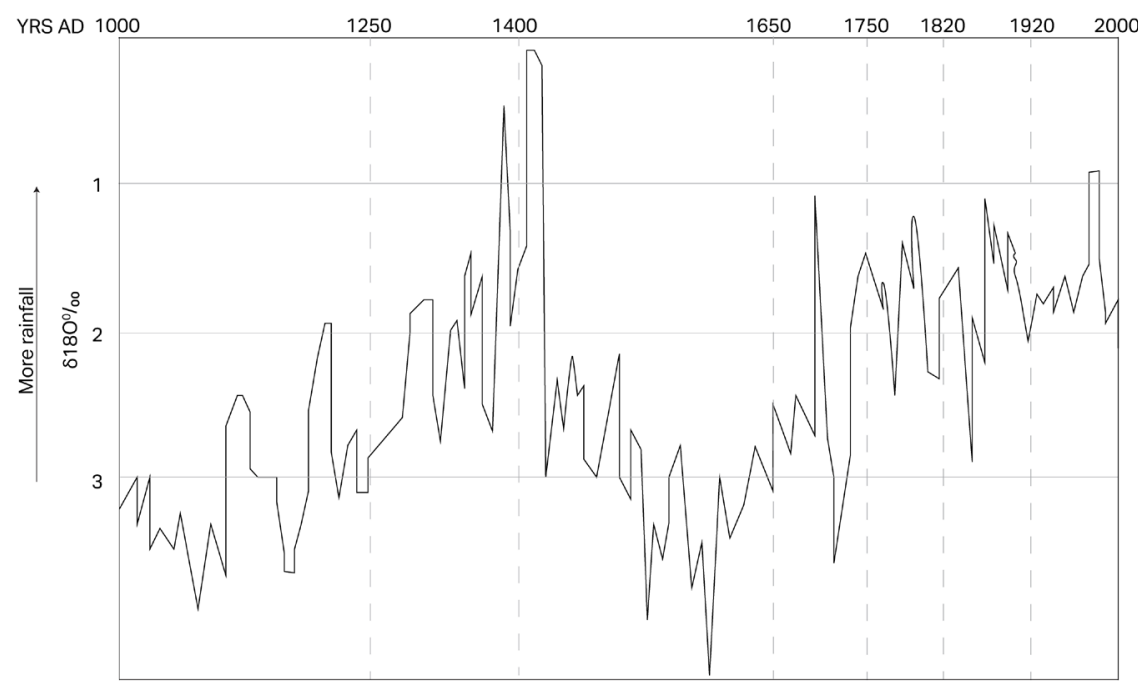

FIGURE 1. Oxygen 18 isotope data from Lake Bosumtwi, Ghana as a proxy for precipitation (based on Shanahan et al. 2009, 379). Period from 1400 to 1650 corresponds to time covered in chapter 2.

1414-1615), based on distinctive pottery forms and radiocarbon dates (Logan and Stahl 2017; Stahl 1999b, 2001, 2007). ${ }^{4}$ Both sites were occupied over several centuries, with people's repeated activities resulting in contexts accumulating on top of one another, forming low mounds across today's landscape. ${ }^{5}$ Multiple mounds were tested at each site in multiple excavation series in the hopes of uncovering domestic, craft working, and midden areas (Stahl 1999b, 2001). Excavating these different kinds of spaces allows us to reconstruct the political economy at Banda at the height of trans-Saharan trade and the later shift to the Atlantic trade.

The early Atlantic era coincides with the worst drought to hit central Ghana in centuries. Paleoenvironmental data from Lake Bosumtwi, located about 200 kilometers south of Banda, indicate markedly arid conditions from about 1400 to $1650 \mathrm{AD}$, with a particularly pronounced spike of aridity around 1400 (figure 1; Shanahan et al. 2009). If modern responses to drought (chapter 5 ) are any indication, we would have expected this far more severe, prolonged drought to have been catastrophic for daily life. In the paragraphs that follow, I attempt to recreate what life might have looked like in this very different version of Banda, following Hegmon and colleagues' (2016) writing conventions, which aim to highlight human experience rather than material remains. For more details on the archaeology of Banda during the mid- to late Kuulo phase, see Stahl's extensive publications (Stahl 1999b, 2001, 2002, 2007, 2015, 2018a, 2018b) as well as a more recent consideration of the relationship between environmental change and exploitation of plants and animals (Logan and Stahl 2017). Data tables are available in appendix B.

While we do not yet know the extent of Ngre Kataa, nearby Kuulo Kataa was one of the largest, densest villages in the Banda area at about twenty-eight hectares 
or the size of fifty-two American football fields (Stahl 1999b, 16). Probably the location of a large regional market (Stahl 2018a), Kuulo Kataa must have been a vibrant place indeed during the height of the trans-Saharan and early Atlantic trade. If we were to walk through the village, we would have seen a wide array of people practicing different crafts. Skilled potters fashioned all of the storage, cooking, and eating vessels one could imagine, with distinctive grooved and stamped decorations along their rims and shoulders (Stahl 1999b). Specialized potters fashioned some of these pots in the village itself, while other shapes and sizes were likely obtained through regional trade mostly east and sometimes west of the hills (Stahl et al. 2008), perhaps in exchange for foodstuffs, as recorded in much later accounts. Women most likely made the pots, if ethnographically known trends held true (Stahl and Cruz 1998). Potters retained a relationship with iron workers, presumably male, attested by the presence of slag temper in vessels (Stahl 2016). Metalworking was extensive at Kuulo Kataa and Ngre Kataa, where men fashioned both iron and imported copper alloys into utilitarian tools like iron hoes, as well as fancy objects in the shape of seated, human-like figures and others mimetic of snakes and used in ritual practices (Stahl 2013, 2015). Rituals were one way that people made sense of and tried to influence events around them, like the rains, as well as to attain other personal and political goals (Logan and Stahl 2017, 1394-95; Stahl 2008, 2015, 2018b). In some households at Kuulo Kataa, people were busy working hippo and elephant ivory for trade with outsiders, filling the high demand for this material at home and abroad (Stahl and Stahl 2004). Locally produced ivory goods may have been exchanged for items of value, such as glass beads from trans-Saharan networks. If recent ethnographic depictions held true, imported beads may have been used in women's nubility rites, thus "inscrib[ing] subcontinental exchange on local bodies" (Stahl 1999b, 37-38).

We cannot yet discriminate many differences in daily life at neighboring Ngre Kataa, except that the village seems to have been smaller and to have lacked a large regional market. Some of these differences may be attributed to the earlier initial occupation of the village, which began in the previous, Ngre phase, from AD 1230 to 1400 (Logan and Stahl 2017, 1361). Potters, metalworkers, and farmers inhabited Ngre Kataa as well, though we have less evidence that people were crafting ivory. Ngre Kataa may have been known for the skilled metalworkers who lived there, as evidence attests to a range of activities including lost wax brass casting (Stahl 2013, 2015). The diverse array of craftspeople present in the Banda area was probably critical to creating and maintaining the region's wealth. In some parts of precolonial Africa, wealth was not measured by the accumulation of goods, but by the accumulation of people with a range of different skill sets (Guyer and Belinga 1995; Richard 2017). While we cannot be sure that this value system applied to Banda specifically, this economic system appears to have been associated with a high degree of resilience to environmental change, as I argue below.

Peoples' relationships with animals were quite extensive, and meat was consumed in a quantity unmatched earlier or later in time (Logan and Stahl 2017; Stahl 
1999b). The casual visitor would have likely seen plenty of sheep and goats roaming the villages, along with cattle, a great variety of birds, including chickens and guinea fowls, fish, and the occasional pig. ${ }^{6}$ Larger domesticates appear to have been butchered into many smaller pieces, perhaps to provide meat to a larger number of people or to facilitate preparation in stews or sauces. But alongside these more common animals were a host of strange and exciting species with colorful pelts and fierce teeth and claws, a veritable menagerie whose origins spanned from the dry savanna to the dense tropical forest (Logan and Stahl 2017; Stahl 1999b). Not only would these animals have provided a range of meaty textures and flavors, from gamey and musky to fatty, but they would have supplied a range of valuable pelts and paraphernalia for chiefs. Highly skilled hunters must have acquired the most dangerous animals, including hyenas, lions, hippos, leopards, and warthogs (Stahl 1999 b, 33). Curiously, peoples' tastes were not satisfied with the animals from the immediate vicinity alone. Many species were acquired from tropical forests some distance away (e.g., various monkeys; Stahl 1999b, 33). A few rare exotics must have come from the coast, including great white sharks (Logan and Stahl 2017), and may have served nondietary purposes such as personal adornment.

Outside of the villages people grew crops which formed the mainstay of their diets. We cannot yet reconstruct the specific range of cultivation techniques used, or how they might differ from those in use today, but archaeobotanical evidence allows us to paint the broad contours of what was grown and how. Unlike in the more arid regions to the north, there is little evidence for monocropping of grains. Instead, people probably practiced shifting cultivation techniques, with fields containing a mix of grains, tubers, beans, and more. We know this because we see so few weedy species mixed in with domesticated crops, which suggests that people harvested those domesticates individually, by hand. ${ }^{7}$

As discussed more fully below, pearl millet appears to have been the staple grain of choice (see appendix B). Its drought-tolerant properties would have made pearl millet an ideal choice during the arid conditions that prevailed beginning around 1400. Farmers may have cultivated both early- and late-maturing pearl millet varieties, although this awaits archaeobotanical confirmation. ${ }^{8}$ Earlymaturing varieties are still cultivated in arid northern Ghana today, and seem to have been cultivated along the coast in the early Atlantic era (see above). This means they may well have been present in Banda, though they were probably replaced by maize later on. Whatever the case may be, mixed farming of pearl millet along with the other crops discussed below would have been an appropriate strategy for managing arid conditions and producing a variety of nutritious crops. Mixed farming may also have facilitated experimentation with new crops like maize, which could be easily slotted into field laboratories with little change in agronomic practice.

What did the wider foodscape look like? What crops were being grown, and what did people eat on a daily basis? What did these foods taste and look like? Before we answer these questions, it is important to note that some crops are more 
visible than others in the archaeological record. Yams and other tubers are almost impossible to find, even though they were probably important staples in the past. Grains and other hard-seeded plants that come into contact with fire are usually the best represented, and this is certainly the case in Banda. But even these grains are not as abundant as at archaeological sites to the north. I suspect this has little to do with the quantities in which they were used, but more to do with the kinds of foods they were made into. In particular, if grains are ground into flour before they are exposed to fire, very few whole grains will survive to be identified under the microscope. The limited written documentation from this period suggests many, if not most, grain-based foods were made from flour on the coast (de Marees [1602] 1987; La Fleur 2012) as well as throughout the drier savanna and Sahel (Lewicki 1974). Lewicki specifies that grains were made into porridges, flatbreads, and fritters (44-49). In Banda, which is situated geographically between the two areas just mentioned, grinding stones are commonly encountered in archaeological deposits from this phase, suggesting that this food preparation technique was quite common.

In order to account for these taphonomic issues, I quantify seed remains in two ways. Ubiquity, measured by the percentage of contexts analyzed where a plant was found, provides an idea of how commonly the plant was used. ${ }^{9}$ Percentage frequency, or the percent of the total grain assemblage that a particular grain occupies (e.g., millet in relation to all grains), allows for comparison of one grain type to another, assuming some similarity in preparation. Further, where we found these seeds is almost as important as their ubiquity or frequency, and details are provided in appendix B. I focused analysis on similar kinds of contexts at Ngre and Kuulo Kataa to facilitate comparison. At each I analyzed a midden mound (KK Mound 101; NK Mound 8) dense with garbage and accumulated over a long time period, in order to capture the range of foods used over time; as well as two structures from each village (NK Mound 7 Upper and Lower Structures; KK Mound 118 and Mound 148), in order to begin looking at similarities and differences in peoples' daily lives.

People primarily depended on pearl millet (44\% average ubiquity, $85 \%$ of total grain assemblage), which has a nutty, earthy taste. ${ }^{10}$ While we can surmise, based on the presence of grinding stones, that pearl millet was probably ground into a flour, it is less clear from the evidence how the flour was prepared. Did people enjoy a dish similar to modern day tuo zafi, a stiff, polenta-like concoction served with sauce (chapter 5 )? While this is a tempting conclusion to draw, we must recall the great spans of time and historical processes between today and the early Atlantic era, a time of considerable flux propelled by innovation and globalization. We know for example that foods like kenkey, a fermented maize product wrapped in leaves, were developed on the coast at this time. A close reading of historical sources raises the possibility that people ate pancake-like flatbreads made of pearl millet. Prepared today on hot rocks by mobile pastoralists, flatbreads were more 
widespread in the past. Referring to the coast in the early seventeenth century, de Marees $(1987,112)$ characterizes pearl millet specifically as

a good and excellent Grain, which is turned into bread without difficulty, since it is not hard to break and is quickly ground into Dough. If they knew how to bake it nicely, it would look like and have the colour of rye-and-wheat bread; but as they do not use any Ovens and only bake on the cold [ = bare] earth with hot ashes, it looks rather like buckwheat Cakes. It has a good taste and is wholesome to eat. It tastes salty, but grits your teeth a little, which results from the stones with which it is ground. ${ }^{11}$

This description suggests that a millet bread, most likely a flatbread given the absence of gluten, was prepared in southern Ghana in the early seventeenth century. Flatbreads are also mentioned in medieval Arabic sources from Sahelian West Africa (Lewicki 1974, 44-49). Based on pottery forms and the presence of earthen ovens, McIntosh (1995) suggests that flatbreads were the dominant food preparation technique in Jenne-Jeno from $400 \mathrm{BC}$ to $500 \mathrm{AD}$, but that the subsequent assemblage (500-1500 AD) is more suggestive of whole grains or cracked grains and stews. She interprets this shift as essentially a change in women's labor that necessitated devoting less time to food preparation. While we do not find clear examples of ovens in Banda, note that these were not necessary for bread preparation on the coast. There are several examples of burned basins which could have served as griddles suitable for flatbread preparation (NK M7 Lower Structure and KK M148), with KK M148 perhaps showing evidence for an oven. Phytoliths, microscopic plant silica structures, suggest at least a moderate probability that pearl millet was indeed used in some of these contexts (NK M7 Lower Structure; see Logan 2012 and appendix A for phytolith identification methods).

However it was prepared, pearl millet would have been a nutritious choice, and given its high drought tolerance, also a good agronomic choice. In fact, Banda normally receives too much rainfall to support optimal pearl millet cultivation, so drought during this time may actually have helped increase production. Yet the wider regional distribution of pearl millet remains suggests a more complicated scenario, as seeds are found in even the wettest part of the subcontinent (e.g., Kahlheber, Bostoen, and Neumann 2009; Kahlheber et al. 2014) in places far too wet for optimal pearl millet cultivation. This, along with the grain's long history in West Africa, suggests a strong cultural preference for this crop even in suboptimal growth zones. Such preference is attested to in Banda as well, as pearl millet dominates even the wettest phases that bookend the Columbian Exchange (for the Ngre phase, AD 1230-1400, see Logan 2012; Logan and Stahl 2017; for the Early Makala phases, 1770 -1820s, see chapter 3 ), when high precipitation levels would have posed serious obstacles to production.

Sorghum, a large globular grain that is sweet to the taste, is also present in the plant remains, but in few contexts and in minute amounts ( $3 \%$ average ubiquity, 
$4 \%$ of the total grain assemblage). While it is present at both Ngre Kataa and Kuulo Kataa, the fact that sorghum's distribution is small suggests it was uncommon across the time range encompassed by these village sites. Sorghum may have been ground or pounded into a starchy staple or perhaps transformed into beer. Beer was probably quite common at Kuulo Kataa, given the preponderance of globular jars with characteristic interior pitting likely caused by the fermentation of an alcoholic beverage (Stahl 2001, 125; Stahl 2018b). Ethnographically, most beer in the area is made of sorghum, but we cannot be certain this was the case in the past. Whatever sorghum was made into, it was probably prepared in individual households, as evidenced by phytoliths likely originating from sorghum in both the upper and lower structures of NK Mound 7.

Maize can have a sweet taste profile like sorghum, though the varieties likely available at its introduction (flint and flour; see Miracle 1965) are much chalkier than the sweet corn commonly found in today's US markets. Maize is present in slightly greater amounts than sorghum ( $11 \%$ of grain assemblage), but with a narrower distribution, as it is only found at Kuulo Kataa, and only in one household (KK Mound 118; 6\% average ubiquity overall). Out of the four households tested, KK Mound 118 stands out, since it is also the only one that yields evidence of ivory objects being manufactured on site (Stahl and Stahl 2004, 95), and since its inhabitants seem to have acquired at least part of their food through trade or exchange (see below). One maize cupule from KK M118 was directly dated via accelerator mass spectrometry (AMS) to AD 1484-166o (at 2 sigma, or $96 \%$ confidence level). Documentary evidence suggests that maize did not arrive on the Ghanaian coast until 1554 (Alpern 1992, 2008), so the Banda maize likely dates to the later part of the date range provided by AMS. Still, this demonstrates the relatively rapid movement of the crop approximately four hundred kilometers inland. Maize might also have arrived via an overland route beginning in Senegambia (La Fleur 2012, 95), which makes sense since most of Banda's connections appear to be directed northwards at this time; few material remains are found signaling coastal connections. Combined, these data suggest a quick but limited adoption of maize in Banda, the implications of which I consider below.

In addition to these staple grains, people also consumed vegetable sources of protein and fat. Cowpeas (black-eyed peas) would have provided a complementary protein. Beans do not preserve as readily as grains (Gasser and Adams 1981), so it is not a surprise that they are present in low quantities in Banda. This also explains the presence of seeds conservatively identified as members of Fabaceae, the legume family, which includes poorly preserved cowpeas and possibly another species of bean. Oils would have been important for fat, flavor, and cooking. The oils available in ancient Banda provided rich, robust flavors: true to its common name, shea butter does have a buttery texture, and when fried provides a savory, aromatic quality to food; palm oil is even richer, velvety, and bright orange in color. Shells from both shea tree nuts and oil palm nuts were found, but in frustratingly 
small quantities of only one fragment each. Given the dry conditions at the time, it is highly unlikely that oil palm could have grown locally (today, under much wetter conditions, it does not); the palm oil or palm nuts were probably obtained via trade. The lack of shea nut shells is more surprising, since these trees do thrive in drier savannas and are often well represented at savanna and Sahelian archaeological sites (Gallagher, Dueppen, and Walsh 2016); their absence points to the collection and production of this oil elsewhere but possibly still somewhere within the Banda region itself. While not cultivated in the strict sense (Gallagher, Dueppen, and Walsh 2016), shea tree stands are encouraged today, and people will travel some distance to collect the nuts.

The role of other wild plants in Banda peoples' diets is difficult to deduce, since most plants that are edible are also medicinal and/or common weeds (see Abbiw 1990). Today for example, leaves from weedy plants are used to make a nutritious soups and sauces that accompanies starchy staples. Several plants used for their edible leaves today (appendix C) were found in archaeological contexts, including Cassia spp. (Nafaanra: bombo), Ocimum sp. (Nafaanra: napun [O. basilicum] or chasigbso [O. gratissimum]), and Laportea aestivans (Nafaanra: klakokagbec). Interestingly, Cassia spp. are used today to impart a desirable slippery texture to soups, one which allows tuo zafi or fufu to slide easily down one's throat without chewing. That this texture was desirable is attested to by the presence of okra in both the earlier Ngre and later Makala times (appendix B; Logan and Stahl 2017). However, it is impossible to say with certainty whether these plants were eaten or simply grew nearby.

Sauces or soups may have been flavored by Ocimum, a wild basil, as well as by grain of paradise (Afromamum melegueta), which provides a peppery, cardamom-like taste. Grain of paradise, or melegueta pepper, was a major trade good at the time, probably originating on the coast and highly desired in Europe from the fifteenth century on (Beichner 1961, 305; Van Harten 1970, 208). Its earliest mentions in European records predate the Atlantic trade (Van Harten 1970, 208-9) and thus suggest that it was initially obtained through trans-Saharan networks rather than coastal ones. This spice is rare in Banda, but the fact that it is present at Ngre Kataa as well as Kuulo Kataa may hint at its role in local cuisine.

Male and female visitors alike might have been offered pipes, since smoking tobacco was rapidly gaining in popularity. Like maize, tobacco was a postColumbian introduction to Africa, hailing originally from the Americas (McIntosh, Gallagher, and McIntosh 2003). Much like maize, tobacco made fast inroads, and we have good evidence that Banda's inhabitants took quickly to smoking. Smoking is highly visible in the archaeological record, since West Africans were quick to fashion distinctive, locally made ceramic smoking pipes which readily preserve. Documentary, botanical, and archaeological evidence suggest multiple introductions of tobacco in the late sixteenth century. Tobacco is recorded at Whydah, on the Atlantic coast, in 1580, and in Timbuktu in 1594/96, suggesting a much earlier 
introduction in Senegambia. It was common at coastal Elmina by 1639/45 (Alpern 1992, 30). The variety traditionally grown in West Africa (prior to large-scale commercial production) is Nicotiana rustica, which is native to eastern North America; this along with other evidence suggests a French introduction through Senegambia (Ozanne 1969; Phillips 1983). ${ }^{12}$

In Banda, people begin using tobacco pipes in the mid- to late Kuulo phase, with dramatic increases by $1600-1700$, indicating a considerably more widespread adoption than maize (Logan and Stahl 2017; Stahl 1999b, 2002). This is particularly impressive since adopting tobacco meant that people also adopted the entirely new practice of smoking; unlike maize, tobacco could not be easily slotted into existing practices. At its first introduction, some individuals at Kuulo Kataa used a variety resembling Nicotiana rustica, judging from the morphology of the seeds (in Mound 118, Nicotiana cf. rustica: 4 and cf. N. rustica: 1; in Mound 148, cf. N. rustica: 1). This restricted pattern hints at a quick but limited adoption, like maize, but unlike maize, tobacco seeds are tiny and do not preserve as readily. The distribution of tobacco pipes is likely a more robust indicator of the distribution of smoking.

\section{LOCAL GRAINS AND FOOD SECURITY DURING DROUGHT}

This world of interconnected and productive craftspeople and traders attested at Banda does not fit easily with imaginaries of an Africa plagued by the worst drought on record for the last millennium. While this drought surely had an impact on crop production and thus food availability, we do not see evidence of coping mechanisms that indicate food insecurity. Maize, for example, was not adopted widely, suggesting that there was little need for additional calories to bridge a hungry season. While wild plants continue to be used, none of these are known famine foods or replacements for staple crops; instead they added taste and texture. The same is true of the wide range of animal species utilized, some of which seem to have been selected for their novelty or rarity rather than ease of capture, more typical in later periods. Indeed, many of these animals, such as the great white shark or the various predatory cats, were likely luxury items. The production of crafts beyond local needs, including luxury items crafted of ivory and copper, is not what one would expect if drought had resulted in widespread crop failure or food shortage. Neither are the imports of other fine goods like beads and the new habit of smoking, or the use of surplus crops for beer production. Farmers clearly adjusted what was being grown to better suit the dry conditions. Pearl millet, a very drought-tolerant crop, was grown and consumed in higher percentages than sorghum.

However, the question that remains is whether locally produced foods were sufficient to maintain Banda's diverse population. The capability of local food 
production to meet local food consumption needs can be addressed by considering both whether food was traded into Banda and the local population size. Unfortunately, it is impossible to reconstruct the exact quantity of grains that were produced in Banda, but two lines of evidence help us answer this question. The first is whether grain was grown locally or had to be acquired through trade. We can look at whether crops were being grown locally through tracking crop byproducts. "Byproduct materials" is a general category that includes all nonseed, inedible plant parts from domesticated grains, primarily glume, bract, and rachis material left over from later stages of processing. In grains, these materials vary in their robustness and their ability to be preserved; sorghum and maize have hard glumes and cupules that preserve nicely when charred. Pearl millet has soft, papery glumes that do not stand up as well to the ravages of charring, making specific identification difficult. These preservation differences make it hard to compare between crops (say maize to pearl millet), since the hard-glumed species will always be overrepresented. But they do tell us that plant processing was occurring in those contexts. The reasoning here is simple: grain was likely traded in relatively clean form, since, especially in premodern contexts, it makes little sense to transport extra bulk.

Villagers thus appear to have been growing their own grain or obtaining it from nearby, though this varies between households. A large trash dump from each village was combed for plant remains, and results indicate that pearl millet was very common, occurring in 93 to 100 percent of midden contexts. Chaff, rachis, and other fragments left over from grain processing were present in every midden and house, but in variable amounts across contexts, with the highest ubiquities observed in Kuulo Kataa's midden (40\% presence, Mound 101) and a household at Ngre Kataa ( $32 \%$ presence, Mound 7 Upper Structure). This is significant when you consider that most of the grain people were eating was pearl millet, and that pearl millet byproducts preserve the least well compared to sorghum and maize. At least some households were processing grains themselves, as suggested by the relatively high ubiquity of pearl millet (32\%) byproducts in the Upper Structure of Mound 7 at Ngre Kataa. This is contrast to the household buried in Mound 118, where only $5 \%$ of contexts contained byproducts, suggesting that this household acquired much of their grain through trade.

These household-level differences suggest grains were traded between households or within the Banda region. This strategy makes sense of the data at hand. We have plenty of evidence that various craft specialists (potters, metalworkers, ivory workers) lived and worked in the region. Archaeologists tend to make the assumption that the presence of full-time specialists implies a certain level of surplus, since not everyone has to take the time to farm. ${ }^{13}$ In Banda, we cannot tell for certain whether people practiced their crafts full- or part-time (perhaps alongside farming, as is common today), but the differences in byproduct remains between households suggests that at least some may have supplemented 
household food supplies with grain from others. While it is impossible to say with certainty, it is likely that foodstuffs like grains were traded between households and on a regional basis. Ethnohistorically there was a strong tradition of exchanging pots for grain, whereby a pot could be obtained by exchanging a volumetrically equivalent amount of grain. We know from Stahl et al's (2008) sourcing study that people obtained pots from different specialists mostly east, but occasionally west, of the Banda hills, and it is quite likely that grains were a part of this regional trade system. In short, it seems likely based on the evidence at hand that the Banda region produced enough grain to feed people, but that grain was traded between households and towns, a social strategy that probably enabled a degree of resilience to local-scale environmental perturbations.

A second line of evidence concerns population: Was production sufficient to support significant populations in the Banda area? This line of reasoning is loosely based on Malthusian assumptions, and is the most common question asked when I deliver talks on food security during the mega-drought. Many people surmise that populations must have been much lower during the mid- to late Kuulo phase in order for diminished food supplies to have been sufficient. Precise population numbers are beyond the reach of most archaeologists, but we can compare the number and size of archaeological sites in one time period with those of another, allowing for a relative assessment of population over time. The Kuulo phase was characterized by aggregation of populations into larger towns (Smith 2008). In fact, there are more large towns on the landscape than in any other archaeological phase (though fewer than today). As later chapters demonstrate, our first evidence for chronic food insecurity is in the mid- to late nineteenth century, when populations appear to be at their lowest (chapter 4). Clearly the predicted relationship between population and food supply does not explain food insecurity in Banda. Instead, the data suggest a far more intriguing possibility: that despite the worst drought on record in a millennium, Banda farmers sustained the largest population in one thousand years.

Banda's case presses the question of whether other ancient African societies were equally well equipped to deal with drought. Unfortunately without equivalent empirical data from archaeological and historical sources, this hypothesis is impossible to adequately assess at present. However, Arabic sources from the interior, drier reaches of West Africa provide tantalizing clues. Lewicki's (1974, 22-24) compilation of Arabic sources mentioning food suggests that food was abundant. For example, Al-Omarī, who wrote between 1342 and 1349 during the height of the Mali Empire, writes that rice, fonio (hungry rice, Digitaria exilis and Digitaria iburua), wheat, and above all sorghum provided ample food for people and animals. He states that this was the case even though the country suffered from several years of drought and continued to supply large quantities of livestock as offerings. Leo Africanus (1526, in Lewicki 1974) found Timbuktu, then a principal city of Gao, as well as Hausaland to the south to be rich in grain. Clearly much work 
remains to be done to evaluate these claims, as well as to establish the relative food security in these important trade centers. Banda's case suggests that we start with a hypothesis of abundance rather than one of privation, and opens up new possibilities for research into African food security across the wider region.

Banda's situation provokes the question of whether people were able to achieve not just food security but food sovereignty. The term food sovereignty in a modern context refers to peoples' rights to foods (as a human right rather than a commodity) and to their control over food resources, often on a regional scale. At present, food sovereignty in Banda during this time is difficult to measure based on the archaeology alone, but the diverse economy of Banda and Africanist scholarship on wealth and value provides some hints. Guyer and Belinga's (1995) wealth-inpeople model established that in some areas of precolonial Africa, people, rather than accumulation of goods, were the main source of wealth. People with a variety of skills sets-potters, iron workers, artisans skilled at working ivory, et cetera.would have been especially valuable because they would have increased the composition of skills. Now, we cannot know how extensive these systems of value were in precolonial Africa or whether they applied to Banda, but they provide a more appropriate model of wealth than do Western capitalist accumulation models. To take the model a step further, food supplies were likely adequate to support the diverse community of craftspeople in Banda. To ensure that people stayed in a region, mechanisms may well have been in place to distribute food even to people who were not primary producers. If not, people of diverse skills sets could have easily voted with their feet (see also Richard 2017). Whether this "moral economy" and the underlying political organization provided food as a right of citizenship is a question worth asking of archaeological data in the future.

\section{RETHINKING THE COLUMBIAN \\ EXCHANGE IN AFRICA}

How can we now understand crop adoption during the Columbian Exchange in Banda, given that food security seems to have been high? Much like scholars of the Columbian Exchange, archaeologists seek to understand why people took new plants and animals into their agricultural and food regimes (Jones et al. 2011). This debate is often framed in terms of necessity versus choice: Did people adopt new foods because they were desperate for them, or in a situation of plenty? This question has only rarely been considered in African contexts, where necessity has often been assumed, as Crosby's argument demonstrates.

Macbeth and Lawry $(1997,4)$ suggest that foodways tend to change the most under the opposing conditions of novelty and of necessity, with less change observed in the vast middle ground. This range of food choice is visible archaeologically through considering the context of food adoptions and their patterns of adoption. Crops adopted out of need to make up for a shortfall tend to be taken 
up quickly and widely (Liu et al. 2014), whereas foods adopted in conditions of luxury are adopted quickly but in a more limited way, by those with the means to do so (Boivin, Fuller, and Crowther 2012). In the case of the Columbian Exchange in Africa, most scholars have assumed that maize was adopted under conditions of deprivation, since the potential of indigenous African grains has long been undervalued. However, the pattern of maize adoption and spread in Banda does not support this model. If maize was adopted to fill a caloric shortfall, we would have expected a quick and widespread pattern outlined for other instances of food globalization (Liu et al. 2014). What I have shown is precisely the opposite: during the early years of the Columbian Exchange, Banda was in its heyday and maintained a high level of food security. This security enabled a much greater control over food choice, perhaps supporting a degree of food sovereignty. Maize shows a quick but limited pattern that suggests its adoption was a social process (cf. Boivin et al. 2012). Tobacco too seems to conform to this model at its earliest introduction, though it quickly became widespread, suggesting uptake by the masses, out of not necessity but desire.

Understanding context, and particularly food security levels, is essential to disentangling why people adopted new foods, as I discuss further in chapter 3 . Mound 118 , for example, seems to have been elite, particularly given its early adoption of maize. But objects acquired from long-distance trade are peppered throughout the other houses and trash deposits. Copper and beads, both acquired from Niger trade networks, are found in all structures. Figurative weights that are ethnohistorically associated with gold-dust trading are found in two structures (Ngre Kataa's M7 Upper Structure and Kuulo Kataa's Mound 118). Cowrie shells, used either as currency or for decoration, are nonlocal and are found in three structures (Banda Research Project 1995, 2009). The point here is that the residents of Mound 118 are hardly unique in their desire for global goods, nor do they represent outlier consumers of luxury goods. While it is interesting that they were early adopters of maize, what is more interesting is that most people were not.

If we focus only on change we miss what the majority of people were eating and why. The data from Banda are unequivocal: pearl millet was the staple grain, before, during, and after the Columbian Exchange and until relatively recently. This crop likely enhanced people's ability to withstand climatic risk in a way that maize never could. It is archaeology's ability to access these everyday choices (Robin 2013) that makes it such a critical archive for understanding food history. While archaeologists tend to privilege change, this obscures what actually went on in the past by making those occupying either the luxury or necessity ends of the spectrum the most visible. But people who fall somewhere in between are perhaps making an even more important choice from the vantage of food security: keeping things the same. Continuity is work, most especially in global encounters, when new foods, things, and ideas provide a new set of options. The desire to keep things the same may well arise in response to global encounters, just as local 
foods movements today are linked to increasing globalization (Wilk 2006b). Such continuities form the basis of tried-and-true traditions that help people weather environmental change and provide a local sense of identity in the face of rapid political economic change. Simply put, if we focused only on change in the form of new crops, we would miss precisely what allowed people to survive the worst drought in the last one thousand years. 